Citation: Sugiyama, T., Shibata, A., Koohsari, M.J., Tanamas, S.K., Oka, K., Salmon, J., Dunstan, D.W., \& Owen, N. (2015). Neighborhood environmental attributes and adults' maintenance of regular walking. Medicine \& Science in Sports \& Exercise. 47(6), 1204-1210. (Accepted 18 September 2014)

\title{
Neighborhood environmental attributes and adults' maintenance of regular walking
}

Takemi Sugiyama, PhD, ${ }^{1,2}$ Ai Shibata, PhD, ${ }^{2,4}$ Mohammad J Koohsari, PhD, ${ }^{2,3}$ Stephanie K Tanamas, PhD, ${ }^{2}$ Koichiro Oka, PhD, ${ }^{2,5}$ Jo Salmon, PhD, ${ }^{6}$ David W Dunstan, PhD, $, 2,6,7,8,9$ Neville Owen, $\mathrm{PhD}^{2,3,7,8}$

${ }^{1}$ School of Population Health, University of South Australia, Adelaide, SA, Australia

${ }^{2}$ Baker IDI Heart and Diabetes Institute, Melbourne, VIC, Australia

${ }^{3}$ School of Population and Global Health, The University of Melbourne, Melbourne, VIC, Australia

${ }^{4}$ Faculty of Health and Sport Sciences, University of Tsukuba, Tsukuba, Japan

${ }^{5}$ School of Sport Sciences, Waseda University, Tokyo, Japan

${ }^{6}$ School of Exercise and Nutrition Sciences, Deakin University, Burwood, VIC, Australia

${ }^{7}$ The University of Queensland, Brisbane, QLD, Australia

${ }^{8}$ Monash University, Melbourne, VIC, Australia

${ }^{9}$ The University of Western Australia, Perth, WA, Australia

\section{Corresponding author}

Neville Owen, $\mathrm{PhD}$

Behavioural Epidemiology Laboratory, Baker IDI Heart and Diabetes Institute

99 Commercial Road, Melbourne, VIC 3004, Australia

Phone: +61 38532 1874, Fax +61 38532 1100, Email: neville.owen@bakeridi.edu.au 
Running title: Environment and walking maintenance

Conflict of interest: All authors declare no conflict of interest.

Funding sources: The study was supported by funding from the National Health and Medical Research Council of Australia. Please refer to the acknowledgments section for further information. 


\begin{abstract}
Purpose: Environmental initiatives to support walking are keys to non-communicable disease prevention, but the relevant evidence comes mainly from cross-sectional studies. We examined neighborhood environmental attributes associated cross-sectionally with walking and those associated prospectively with walking maintenance.
\end{abstract}

Methods: Data were from the Australian Diabetes, Obesity and Lifestyle study collected in 2004-05 (baseline) and in 2011-12 (follow-up). Participants who did not move residence during the study period ( $\mathrm{n}=2684$, age range: $30-77$ at baseline) were categorized as regular walkers (walked 5 times/week or more) or not at baseline. Regular walkers were divided into those who stopped and those who maintained regular walking at follow-up. Regression analyses examined relationships of regular walking and walking maintenance with perceived attributes of neighborhood destinations and pedestrian environments.

Results: Regular walking at baseline was significantly associated with availability of shops (OR: 1.13, 95\%CI: 1.04, 1.22), many alternative routes (OR: 1.12, 95\%CI: 1.01, 1.23), park or nature reserve (OR: 1.13, 95\%CI: 1.02, 1.26), bicycle or walking tracks (OR: 1.08, 95\%CI: 1.00, 1.17), and feeling safe to walk (OR: 1.18, 95\%CI: 1.01, 1.38). The maintenance of regular walking was associated with availability of multiple alternative routes (OR: 1.19, 95\%CI: 1.03, 1.38). Having many alternative routes and walking tracks were associated with walking maintenance among those who were not or had stopped working.

Conclusion: Neighborhood destinations (shops, parks) and pedestrian environments (alternative routes, walking trails, safety from crime) were found to be associated with regular walking, but only pedestrian environment attributes were found to be related to the 
maintenance of regular walking. Further evidence from prospective studies is required to identify other neighborhood environmental attributes that might support walking maintenance.

Keywords: physical activity, adherence, cross-sectional studies, prospective studies 


\section{Introduction}

Paragraph Number 1 Promoting regular walking - a realistic physical activity option across most age groups - is a key public health strategy for non-communicable disease prevention $(14,21)$. However, large-scale studies show the proportion of adults who walk sufficiently to obtain health benefits to be low $(13,20)$. Environmental and policy initiatives have the potential to bring about sustainable, wide-scale improvements in walking participation (28). In contrast to promotion strategies focusing on individuals, it is expected that environmental interventions will have long-term impacts on residents’ maintenance of walking behaviors (28).

Paragraph Number 2 Reviews have identified neighborhood destinations (e.g., stores, services, recreational facilities) and street-related attributes (e.g., connectivity, pedestrian infrastructure) to be associated with residents' walking (23, 26, 32, 34). However, most of the existing studies on this topic are cross-sectional in design $(26,34)$. Prospective studies identifying particular neighborhood environmental attributes that help residents to maintain regular walking are needed to provide stronger evidence to inform environmentally-focused initiatives. There is a small body of evidence on environmental factors relevant to the maintenance of walking among adults. A study in Canada found the proximity to services and amenities to be conducive to older adults' continued walking over a 3-year period (12). In the USA, it was found that older adults living in safe walking environments with easy access to activity facilities (e.g., parks) were less likely to decrease walking (15). In Australia, the presence of and proximity to green spaces were found to be associated with the maintenance of recreational walking among adults (31). However, studies to date do not seem to have examined explicitly whether environmental attributes associated cross-sectionally with adults walking can also support the maintenance of walking behaviors. 
Paragraph Number 2a In examining prospective relationships between walking behaviors and environmental attributes, life changes may also influence long-term walking patterns. Work status may be particularly relevant, as whether a person is working or not working is likely to impact walking behaviors as well as levels of exposure to local environments. Those who are working may walk regularly for transport, while non-working adults are more likely to spend longer time in their local areas, and may walk more for recreation. Research has shown that neighborhood environmental attributes are more closely associated with nonemployed adults’ walking (8). Work status and its change may moderate associations of environmental attributes with regular walking and with walking maintenance.

Paragraph Number 3 We examined neighborhood environmental attributes associated crosssectionally with regular walking and those associated prospectively with the maintenance of regular walking over seven years, among a sample of adults in the Australian Diabetes, Obesity and Lifestyle (AusDiab) study. We also examined whether work status modified such relationships.

\section{Methods}

Study sample

Paragraph Number 4 The AusDiab study is a prospective cohort study that was established originally to examine the prevalence and correlates of diabetes and related risk factors. Detailed methods of sample recruitment and data collection have been described elsewhere (5, 33). Briefly, there were three waves of data collection: AusDiab1 (1999-2000); AusDiab2 (2004-2005); and AusDiab3 (2011-12). The present study used AusDiab2 as baseline and AusDiab3 as follow-up due to unavailability of exposure measures (environmental attributes) in AusDiab1. In AusDiab1 ( $\mathrm{n}=11,247)$, the sample was drawn from private dwellings within 
42 clusters of Census Collection Districts (CCD, a geographic unit defined by the Australian Bureau of Statistics with an average of 225 dwellings each). Six CCD clusters were randomly selected from each of seven Australian states and territory. More information about the study areas and recruitment methods can be found within the AusDiab website (http://www.bakeridi.edu.au/ausdiab/publications/). Questions on neighborhood environments were introduced in AusDiab2 ( $n=6,400)$, which is the baseline of the current study. The follow-up survey (AusDiab3) was conducted, on average, 6.9 (SD: 0.3) years after the baseline. The sample of this study consisted of those who participated in both the baseline and follow-up surveys $(n=4,802)$. Of these, participants who moved residence between the surveys $(n=1,650)$, were older than 85 years at follow-up $(n=127)$, had missing data on walking at baseline or at follow-up ( $\mathrm{n}=201)$, had missing data on environmental variables $(\mathrm{n}=34)$, had problems in walking 100m due to health at follow-up $(\mathrm{n}=392)$, and lived in care facilities during the past 3 months at follow-up ( $n=27)$ were excluded (numbers not mutually exclusive). The reason for excluding those with limited physical functional capacities was that their behavior changes may have been attributable largely to their functional status.

Participants over 85 years at follow-up (over 78 years at baseline) were also excluded because a study has shown considerable functional decline after 78 years of age (29). The final sample size was 2,684. Written informed consent was obtained from all participants. The study was approved by the Ethics Committee of International Diabetes Institute and The Alfred Health Human Ethics Committee.

Measures and instruments

Paragraph Number 5 Outcome measures. Walking was assessed using the Active Australia Survey both at baseline and follow-up (1). Participants were asked to report the frequency of walking for recreation, exercise and transport in the last week (for at least 10 minutes at one 
time). Although walking duration was available, we used frequency of walking, as overreporting of duration is common in instruments that ask about the duration of activity in the last seven days (25). Several recent studies have also used walking frequency in light of concerns about accuracy of walking duration $(12,18)$. The walking frequency item of this instrument was shown to have moderate test-retest reliability (Spearman's $\rho=0.58$ ) and moderate criterion validity (Spearman's $\rho=0.40$ ) against accelerometry (3). At baseline, participants who reported walking 4 times/week or less were classified as "non-regular walkers”, and those who reported 5 times/week or more were classified as "regular walkers”. Regular walkers at baseline were further divided into those who "stopped regular walking” (reporting 4 times/week or less at follow-up) and those who “maintained regular walking” (reporting 5 times/week or more at follow-up). Five times/week was chosen as a cut-off, since current guidelines for physical activity recommended 5 days/week or more (11), or 5 sessions/week or more (2).

Paragraph Number 6 In order to distinguish regular and non-regular walking more clearly and to reduce the possibility of misclassification, an alternative categorization in which those who reported walking 3-4 times/week were removed was also examined. In this categorization, cross-sectional analyses compared regular walkers (5 times/week or more) and non-regular walkers (0-2 times/week) to identify environmental correlates of regular walking. Similarly, prospective analyses compared those who maintained 5 times/week or more at both time points and those who decreased from 5 times/week or more at baseline to 0-2 times/week at follow-up.

Paragraph Number 7 Exposure measures. Neighborhood environmental attributes were measured at baseline using self-report. They included the following nine items: many stores 
within easy walking distance; many alternative routes to get to places; footpaths on all streets; park or nature reserve nearby; bicycle or walkway tracks nearby; attractive neighborhood; pleasant natural features in neighborhood; local traffic not making walking difficult or unpleasant (reversed from the original survey item); and feeling safe to walk during the day. These environmental items were extracted from the Neighborhood Environment Walkability Scale, for which reasonable test-retest reliability has been reported (27). Participants were asked to assess these items in their local area, which was defined as the area within a 10- to 15-minute walk from home. The response format ranged from 1 (strongly disagree) to 4 (strongly agree), and each item was treated as a continuous measure.

Paragraph Number 8 Covariates. The following socio-demographic characteristics were asked at baseline: gender; age; education attainment (less than high school, high school, tertiary); work status (working full-time or part-time, not working); marital status; having child in household; and annual household income (AU\$41,599 or less, AU\$41,600-77,999, AU\$78,000 or more, no reporting). Since the change in participants’ life status may influence their long-term walking patterns, the change in work status, marital status and the presence of children in household were determined using participants' response at follow-up. For instance, participants were classified into those who kept working, stopped working, started working and not working. In addition, participants’ baseline functional status (having some problem in walking) and their baseline BMI calculated from measured weight and height were also used as covariates. Participants with severely limited mobility (having problem in walking $100 \mathrm{~m}$ ) at follow-up were excluded from the sample, and analyses adjusted for baseline functional status to account for reduced mobility of older adults included in the AusDiab study. 
Statistical analysis

Paragraph Number 9 Logistic regression analysis examined associations of each environmental attribute with regular walking (cross-sectional) and the maintenance of regular walking (prospective), adjusting for covariates that were associated with the outcome in univariate analysis $(\mathrm{p}<0.1)$. Multilevel mixed-effects logistic regression, using each environmental attribute as an individual-level continuous predictor and CCD cluster $(n=42)$ as a random intercept, was used. Cross-sectional analyses were conducted for those who completed both the baseline and follow-up surveys. Interaction between each environmental attribute and work change status was examined. Stratified analyses were conducted when the interaction was significant $(\mathrm{p}<0.1)$. Participants who started working were excluded from the interaction/stratified analyses as they constituted a small percentage of the sample (6\%). Analysis was conducted using Stata12 (STATA Corporation, College Station, TX).

\section{Results}

Paragraph Number 10 Figure 1 shows how participants were categorized based on their walking frequency at baseline and follow up. About two-fifths of participants were regular walkers at baseline. Of those, approximately two-thirds maintained regular walking at followup. Table 1 shows the characteristics of the study sample and those of each walking category. Participants' age ranged from 30 to 77 at baseline. Table 1 shows that baseline age gender, education, mobility, BMI, and the change in work status and in parenthood status were associated with either regular walking or regular walking maintenance at $\mathrm{p}<0.1$ in univariate analyses (t-tests for continuous variables, and chi-square tests for categorical variables). Regression analyses (both cross-sectional and prospective) adjusted for these covariates. In the alternative categorization (treating only those walking $0-2$ times/week at baseline as being non-regular walkers), $50 \%$ of the total sample were regular walkers at baseline, and $78 \%$ of 
regular walkers maintained regular walking at follow-up (Figure 1).

\section{(INSERT FIGURE 1 AND TABLE 1 ABOUT HERE)}

Paragraph Number 11 Table 2 shows the mean (standard deviation) of each environmental attribute and the odds of regular walking (cross-sectional) and of maintaining regular walking (prospective) for each environmental attribute, adjusting for the covariates discussed above. Most of these environmental attributes were not closely correlated, except for a few moderate correlations ( $r<0.5$, correlation coefficients are shown in Supplemental Digital Content 1). Cross-sectional analyses found that having many stores, having many alternative routes, having a park or nature reserve, having bicycle or walkway tracks, and feeling safe to walk during the day in their neighborhood were associated with a higher likelihood of being a regular walker at baseline. Prospective analyses found that participants who had many alternative routes in their local area were more likely to maintain regular walking at followup. In analyses using the alternative walking categorization, regular walking was associated with the same environmental attributes and with having pleasant natural features in the neighborhood. Having multiple alternative routes was also associated with regular walking maintenance for the alternative categorization.

(INSERT TABLE 2 ABOUT HERE)

Paragraph Number 12 A significant interaction with work change status was found for having many alternative routes $(\mathrm{p}=0.07)$ in cross-sectional analyses. In prospective analyses, interactions with work change status were significant for having many alternative routes ( $p=0.08)$, footpaths $(p=0.03)$, a park and nature reserve $(p=0.04)$, and bicycle or walkway tracks ( $\mathrm{p}=0.02)$. The results of stratified analyses for these variables are shown in Table 3. 
Having many alternative routes was associated with regular walking as well as the maintenance of regular walking only among "non-working” participants (those who were not working or had stopped working). Having bicycle or walkway tracks nearby was associated with the maintenance of regular walking only among non-working participants. For the other environmental attributes, stratified analyses showed that the two groups differed in the direction of associations (negative associations for those who kept working, positive associations for non-working participants), but the relationships were not statistically significant. For the alternative walking categorization, no significant interaction was found in cross-sectional analyses, but the same pattern of moderations was found for regular walking maintenance.

\section{(INSERT TABLE 3 ABOUT HERE)}

\section{Discussion}

Paragraph Number 13 In this cohort of Australian adults, neighborhood environmental attributes associated prospectively with the maintenance of walking were found to be different from correlates of walking identified in cross-sectional analyses. Having many alternative routes (i.e., high street connectivity) was the only environmental attribute that was commonly associated cross-sectionally and prospectively. Access to bicycle and walking tracks was associated with regular walking at baseline for the whole sample, and with the maintenance of walking only among those who did not work or had stopped working. These findings were also observed for the alternative categorization of regular and non-regular walking. Three environmental attributes, the presence of footpaths, attractiveness, and local traffic, were associated neither with regular walking nor with walking maintenance. Differences between cross-sectional and prospective analyses were observed for the following attributes: having many stores nearby; having open spaces such as parks; and feeling safe to walk during the 
day. These were significantly associated cross-sectionally with regular walking, but not with the maintenance of regular walking. The findings of having stores nearby are consistent with existing cross-sectional studies reporting the relevance of non-residential destinations to walking $(16,19,22,32)$. Studies on safety from crime and physical activity have reported mixed findings (9), yet there are some recent studies that have shown positive associations between perceived safety from crime and walking $(6,30)$. These findings suggest that some environmental correlates of walking identified in the existing cross-sectional studies may not necessarily help adult residents to maintain their walking over a period of time.

Paragraph Number 14 It may be argued from the present findings that pedestrian or route environments (alternative routes, walking trails) may be important to encourage long-term maintenance of regular walking, while both destinations (stores, parks) and pedestrian environments (alternative routes, walking trails, and safety from crime) are relevant to regular walking at one point in time. An obvious question is why environmental attributes that are associated cross-sectionally with walking are not related to walking maintenance. For instance, why was the presence of stores, which has been consistently shown as a correlate of walking, not associated with maintenance? Our findings do not provide an empirical answer to this question. However, it may be that those who maintained walking over a period of time have established a habit of walking, and habitual and non-habitual walking may be influenced by different environmental factors. For habitual walkers, what matters may be the availability of walkable pedestrian environments. On the other hand, for non-habitual or occasional walkers, decisions to walk may be dependent more on the presence of places to walk to. It has been shown that motivational/attitudinal factors are relevant to the maintenance of physical activity (4). Further research exploring individual, social and environmental factors that would contribute to adults' walking habit is warranted. 
Paragraph Number 15 It was found that having many alternative routes and access to walking tracks were the only environmental attributes relevant both to regular walking and to maintenance of regular walking. Intersection density was found to be associated with walking in previous cross-sectional studies $(17,36)$. Stratified analyses found that significant associations of having many alternative routes with walking were observed for participants who stopped or were not working. The pronounced association for non-workers or those who had stopped working was obtained perhaps because they tended to be more exposed to local environments. However, it is not totally clear whether well-connected street network is conducive to regular walking and to walking maintenance simply due to the availability of more direct route options or due to other environmental or social factors that coexist with higher street connectivity. A study examining the mechanisms through which street connectivity influences walking could provide useful insights into how to facilitate walking maintenance. Walking trails appear to be an important resource to support regular walking. Recent natural experiments have found an increase in walking after an urban trail was built or retrofitted $(7,35)$. However, research on this type of walking facility is relatively limited, compared to studies on neighborhood walkability or on public open spaces. Further studies on attributes of walking trails that can contribute to habitual walking will provide relevant information that helps promote walking through the increased use of this resource.

\section{Limitations and strengths}

Paragraph Number 16 Several limitations need to be considered in interpreting the present findings and identifying fruitful directions for future research. Walking categories were created using a self-report question with a short timeframe (the last seven days) at baseline and follow-up. Fluctuation in walking behaviors that could have occurred during the study 
period may have led to misclassification of participants. In addition, regular walking and walking maintenance were determined using the cut-point of 5 times/week, which corresponds to current physical activity guidelines (11). Although the alternative categorization produced similar results, these categories may have also misclassified participants. Measures that can accurately characterize long-term patterns of walking need to be developed.

Paragraph Number 17 The walking measure used for the study incorporated both walking for transportation and for recreation. Review articles show consistently that these walking domains are associated with different environmental attributes because they tend to take place in different settings $(26,32)$. Thus, it is possible that combining them has masked the relationship between a specific type of walking and an attribute that may actually have existed. A further limitation is that there may have been some environmental changes between baseline and follow-up. A recent longitudinal study has shown increases in recreational facilities around home to be associated with a less pronounced decline in recreational physical activity (24). However, it is unlikely that such changes happened in a systematic way across study areas (e.g., areas with more destinations where people walked regularly at baseline lost destinations at follow-up).

Paragraph Number 18 Participants who have a habit of walking may have chosen to live in a local area with particular attributes. A cross-sectional study found that both neighborhood walkability and attitudes toward active travel accounted for residents' walking behaviors (10). However, the impact of self-selection and attitudinal factors on a long-term walking pattern needs to be examined in future prospective studies. Further, a relatively small number of environmental attributes were used in the study, and they may have missed some relevant 
environmental characteristics. The response options for these items were four integers $(1,2,3$, and 4), which may be a metric that is too crude for examining complex relationships (e.g., non-linear associations) between environmental attributes and walking outcomes. In addition, there may be other interpersonal, intrapersonal, and area-level characteristics (e.g., attitude toward activity, social ties, social norms) that may have confounded the relationships between walking and environmental attributes.

Paragraph Number 19 Strengths of the study include its large sample size, longitudinal design and consideration of the change in life circumstances (work status, household composition). Since participants were recruited from diverse locations (urban, suburban, and regional) throughout Australia, our findings may be applicable to broader settings in a similar context. However, the generalizability of the findings to localities with different environmental characteristics (e.g., Europe or Asia with higher residential density) remains to be determined. We have also used multiple criteria to exclude participants who were likely to have difficulty walking around, in order to minimize the inclusion of participants who stopped walking due to decline in functional capacity.

\section{Conclusion}

Paragraph Number 20 In summary, this study found that neighborhood environmental attributes associated cross-sectionally with adults’ regular walking were not necessarily related to the maintenance of regular walking. Our findings suggest that better pedestrian environments (well-connected street network, access to walking trails) may contribute to the maintenance of walking behavior. Given the importance of long-term habitual walking for health benefits, more prospective studies are needed to further explicate these relationships. 


\section{Acknowledgments}

The AusDiab study was co-coordinated by the Baker IDI Heart and Diabetes Institute. We gratefully acknowledge the support and assistance given by: K. Anstey, B. Atkins, B. Balkau, E. Barr, A. Cameron, S. Chadban, M. de Courten, A. Kavanagh, D. Magliano, S. Murray, K. Polkinghorne, J. Shaw, T. Welborn, P. Zimmet and all the study participants. For funding or logistical support, we are grateful to: National Health and Medical Research Council (NHMRC: \#233200, \#1007544), Australian Government Department of Health and Ageing, Abbott Australasia Pty Ltd, Alphapharm Pty Ltd, Amgen Australia, AstraZeneca, BristolMyers Squibb, City Health Centre-Diabetes Service-Canberra, Department of Health and Community Services - Northern Territory, Department of Health and Human Services Tasmania, Department of Health - New South Wales, Department of Health - Western Australia, Department of Health - South Australia, Department of Human Services Victoria, Diabetes Australia, Diabetes Australia Northern Territory, Eli Lilly Australia, Estate of the Late Edward Wilson, GlaxoSmithKline, Jack Brockhoff Foundation, Janssen-Cilag, Kidney Health Australia, Marian \& FH Flack Trust, Menzies Research Institute, Merck Sharp \& Dohme, Novartis Pharmaceuticals, Novo Nordisk Pharmaceuticals, Pfizer Pty Ltd, Pratt Foundation, Queensland Health, Roche Diagnostics Australia, Royal Prince Alfred Hospital, Sydney, Sanofi Aventis, and sanofi-synthelabo. Koohsari was supported by NHMRC Program Grant \#569940. Salmon was supported by NHMRC Principal Research Fellowship \#1026216. Dunstan was supported by Australian Research Council Future Fellowship. Owen was supported by NHMRC Program Grant \#569940, NHMRC Senior Principal Research Fellowship \#1003960. Authors from Baker IDI Heart and Diabetes Institute were supported by the Victorian Government's Operational Infrastructure Support Program. The results of the present study do not constitute endorsement by ACSM.

Conflict of interest: All authors declare no conflict of interest. 


\section{References}

1. Armstrong T, Bauman A, Davies J. Physical Activity Patterns of Australian Adults. Canberra: Australian Institute of Health and Welfare. 2000. [cited 2014 June 11]. Available from: http://aihw.gov.au/WorkArea/DownloadAsset.aspx?id=6442454841.

2. Australian Bureau of Statistics. Australian Health Survey: Users’ Guide, 2011-13. Canberra: Australian Bureau of Statistics 2013. [cited 2014 June 11]. Available from: http://www.abs.gov.au/ausstats/abs@.nsf/mf/4363.0.55.001.

3. Brown WJ, Burton NW, Marshall AL, Miller YD. Reliability and validity of a modified self-administered version of the Active Australia physical activity survey in a sample of mid-age women. Aust NZ J Public Health. 2008;32(6):535-41.

4. Conroy DE, Hyde AL, Doerksen SE, Ribeiro NF. Implicit attitudes and explicit motivation prospectively predict physical activity. Ann Behav Med. 2010;39(2):112-118.

5. Dunstan DW, Zimmet PZ, Welborn TA, et al. The Australian Diabetes, Obesity and Lifestyle Study (AusDiab): methods and response rates. Diabetes Res Clin Pract. 2002;57(2):119-129.

6. Evenson KR, Block R, Roux AVD, McGinn AP, Wen F, Rodriguez DA. Associations of adult physical activity with perceived safety and police-recorded crime: the Multi-Ethnic Study of Atherosclerosis. Int J Behav Nutri Phys Activ. 2012;9:146.

7. Fitzhugh EC, Bassett DR, Jr, Evans MF. Urban trails and physical activity: a natural experiment. Am J Prev Med. 2010;39(3):259-262.

8. Forsyth A, Oakes JM, Lee B, Schmitz KH. The built environment, walking, and physical activity: Is the environment more important to some people than others? Transport Res D-Tr E. 2009;14(1):42-49.

9. Foster S, Giles-Corti B. The built environment, neighborhood crime and constrained physical activity: an exploration of inconsistent findings. Prev Med. 2008;47(3):241-251. 
10. Frank LD, Saelens BE, Powell KE, Chapman JE. Stepping towards causation: Do built environments or neighborhood and travel preferences explain physical activity, driving, and obesity? Soc Sci Med. 2007;65(9):1898-1914.

11. Garber CE, Blissmer B, Deschenes MR, et al. American College of Sports Medicine position stand. Quantity and quality of exercise for developing and maintaining cardiorespiratory, musculoskeletal, and neuromotor fitness in apparently healthy adults: guidance for prescribing exercise. Med Sci Sports Exerc. 2011;43(7):1334-1359.

12. Gauvin L, Richard L, Kestens Y, et al. Living in a well-serviced urban area is associated with maintenance of frequent walking among seniors in the VoisiNuAge Study. $J$ Gerontol B-Psychol. 2012;67(1):76-88.

13. Kruger J, Ham SA, Berrigan D, Ballard-Barbash R. Prevalence of transportation and leisure walking among US adults. Prev Med. 2008;47(3):329-334.

14. Lee IM, Buchner DM. The importance of walking to public health. Med Sci Sports Exerc. 2008;40(7):S512-S518.

15. Li FZ, Fisher KJ, Brownson RC. A multilevel analysis of change in neighborhood walking activity in older adults. J Aging Phys Activ. 2005;13(2):145-159.

16. Li FZ, Fisher KJ, Brownson RC, Bosworth M. Multilevel modelling of built environment characteristics related to neighbourhood walking activity in older adults. J Epidemiol Community Health. 2005;59(7):558-564.

17. Marshall WE, Garrick NW. Effect of street network design on walking and biking. Transp Res Record. 2010;2198:103-115.

18. Mason P, Kearns A, Livingston M. "Safe Going”: the influence of crime rates and perceived crime and safety on walking in deprived neighbourhoods. Soc Sci Med. 2013;91(1):15-24.

19. McCormack GR, Giles-Corti B, Bulsara M. The relationship between destination 
proximity, destination mix and physical activity behaviors. Prev Med. 2008;46(1):33-40.

20. Merom D, van der Ploeg HP, Corpuz G, Bauman AE. Public health perspectives on household travel surveys: active travel between 1997 and 2007. Am J Prev Med. 2010;39(2):113-121.

21. Murtagh EM, Murphy MH, Boone-Heinonen J. Walking: the first steps in cardiovascular disease prevention. Curr Opin Cardiol. 2010;25(5):490-496.

22. Nathan A, Pereira G, Foster S, Hooper P, Saarloos D, Giles-Corti B. Access to commercial destinations within the neighbourhood and walking among Australian older adults. Int J Behav Nutri Phys Activ. 2012;9:133.

23. Owen N, Humpel N, Leslie E, et al. Understanding environmental influences on walking: review and research agenda. Am J Prev Med. 2004;27(1):67-76.

24. Ranchod YK, Diez Roux AV, Evenson KR, Sanchez BN, Moore K. Longitudinal associations between neighborhood recreational facilities and change in recreational physical activity in the Multi-Ethnic Study of Atherosclerosis, 2000-2007. Am J Epidemiol. 2014;179(3):335-343.

25. Rzewnicki R, Vanden Auweele Y, De Bourdeaudhuij I. Addressing overreporting on the International Physical Activity Questionnaire (IPAQ) telephone survey with a population sample. Public Health Nutr. 2003;6(3):299-305.

26. Saelens BE, Handy SL. Built environment correlates of walking: a review. Med Sci Sports Exerc. 2008;40(7):S550-S566.

27. Saelens BE, Sallis JF, Frank LD. Environmental correlates of walking and cycling: findings from the transportation, urban design, and planning literatures. Ann Behav Med. 2003;25(2):80-91.

28. Sallis JF, Owen N, Fisher EB. Ecological models of health behavior. In: Glanz K, Rimer BK, Viswanath K, editors. Health Behavior and Health Education: Theory, Research, 
and Practice, 4th edition. San Francisco: Jossey-Bass; 2008. p. 465-486.

29. Stessman J, Hammerman-Rozenberg R, Cohen A, Ein-Mor E, Jacobs JM. Physical activity, function, and longevity among the very old. Arch Intern Med. 2009;169(16):1476-83.

30. Sugiyama T, Cerin E, Owen N, et al. Perceived neighbourhood environmental attributes associated with adults' recreational walking: IPEN Adult study in 12 countries. Health Place, 2014;28:22-30.

31. Sugiyama T, Giles-Corti B, Summers J, du Toit L, Leslie E, Owen N. Initiating and maintaining recreational walking: a longitudinal study on the influence of neighborhood green space. Prev Med. 2013;57(3):178-182.

32. Sugiyama T, Neuhaus M, Cole R, Giles-Corti B, Owen N. Destination and route attributes associated with adults’ walking: a review. Med Sci Sports Exerc. 2012;44(7):1275-1286.

33. Thorp AA, Healy GN, Owen N, et al. Deleterious associations of sitting time and television viewing time with cardiometabolic risk biomarkers: Australian Diabetes, Obesity and Lifestyle (AusDiab) study 2004-2005. Diabetes Care. 2010;33(2):327-334.

34. Van Holle V, Deforche B, Van Cauwenberg J, et al. Relationship between the physical environment and different domains of physical activity in European adults: a systematic review. BMC Public Health. 2012;12:807.

35. West ST, Shores KA. The impacts of building a greenway on proximate residents' physical activity. J Phys Activ Health. 2011;8(8):1092-1097.

36. Wilson L-AM, Giles-Corti B, Burton NW, Giskes K, Haynes M, Turrell G. The association between objectively measured neighborhood features and walking in middleaged adults. Am J Health Promot. 2011;25(4):e12-e21. 
Table 1 Characteristics of the study sample by walking categories

\begin{tabular}{|c|c|c|c|c|c|}
\hline \multirow[b]{2}{*}{$\begin{array}{l}\text { Baseline characteristics } \\
\text { (except for change variables) }\end{array}$} & \multirow[b]{2}{*}{ Total } & \multicolumn{2}{|c|}{ Cross-sectional } & \multicolumn{2}{|c|}{ Prospective } \\
\hline & & $\begin{array}{l}\text { Non-regular } \\
\text { walkers }\end{array}$ & $\begin{array}{l}\text { Regular } \\
\text { walkers }\end{array}$ & $\begin{array}{c}\text { Stopped } \\
\text { regular } \\
\text { walking }\end{array}$ & $\begin{array}{c}\text { Maintained } \\
\text { regular } \\
\text { walking }\end{array}$ \\
\hline N (\%) & 2,684 & $1,625(61)$ & 1,059 (39) & $366(35)$ & $693(65)$ \\
\hline Gender, $\%$ men $^{a}$ & 44 & 42 & 48 & 48 & 47 \\
\hline Age, mean (SD) ${ }^{a}$ & $54.4(10.1)$ & $54.1(10.3)$ & $54.8(9.7)$ & $55.2(9.8)$ & $54.7(9.6)$ \\
\hline \multicolumn{6}{|l|}{ Education attainment, $\%^{\mathrm{a}}$} \\
\hline less than high school & 33 & 36 & 28 & 31 & 27 \\
\hline high school & 23 & 22 & 23 & 24 & 22 \\
\hline tertiary & 44 & 42 & 49 & 45 & 51 \\
\hline \multicolumn{6}{|l|}{ Change in working status, $\%^{\mathrm{a}, \mathrm{b}}$} \\
\hline kept working & 40 & 41 & 40 & 35 & 42 \\
\hline stopped working & 17 & 18 & 16 & 20 & 15 \\
\hline started working & 6 & 5 & 7 & 5 & 8 \\
\hline not working & 20 & 19 & 21 & 22 & 21 \\
\hline unknown (missing) & 17 & 17 & 16 & 18 & 14 \\
\hline \multicolumn{6}{|l|}{ Change in child status, $\%^{\mathrm{a}, \mathrm{b}}$} \\
\hline kept living with child & 23 & 25 & 20 & 17 & 21 \\
\hline stopped living with child & 16 & 16 & 16 & 19 & 15 \\
\hline started living with child & 3 & 3 & 3 & 3 & 3 \\
\hline not living with child & 43 & 41 & 47 & 43 & 48 \\
\hline unknown (missing) & 15 & 15 & 14 & 18 & 13 \\
\hline \multicolumn{6}{|l|}{ Change in marital status, $\%$} \\
\hline kept living with partner & 68 & 68 & 68 & 66 & 69 \\
\hline stopped living with partner & 4 & 4 & 4 & 4 & 4 \\
\hline started living with partner & 2 & 2 & 2 & 2 & 1 \\
\hline not living with partner & 11 & 11 & 12 & 10 & 12 \\
\hline unknown (missing) & 15 & 15 & 14 & 18 & 13 \\
\hline \multicolumn{6}{|l|}{ Annual household income, \% } \\
\hline$\$ 41,599$ or less & 37 & 37 & 37 & 39 & 35 \\
\hline$\$ 41,600-\$ 77,999$ & 30 & 30 & 29 & 28 & 30 \\
\hline$\$ 78,000$ or more & 31 & 31 & 32 & 31 & 33 \\
\hline no reporting & 2 & 2 & 2 & 2 & 2 \\
\hline Mobility, \% problem in walking ${ }^{a}$ & 12 & 13 & 10 & 12 & 10 \\
\hline $\mathrm{BMI}$ in $\mathrm{kg} / \mathrm{m}^{2}$, mean (SD) ${ }^{\mathrm{a}}$ & $27.4(4.9)$ & $27.6(5.1)$ & $27.1(4.6)$ & $27.4(4.7)$ & $26.9(4.6)$ \\
\hline
\end{tabular}


Table 2 Odds ratios (95\%CI) of regular walking and maintenance of regular walking by environmental attributes

\begin{tabular}{llll}
\hline Environmental attributes & Mean (SD) & $\begin{array}{l}\text { Cross-sectional } \\
(\mathrm{N}=2684)\end{array}$ & $\begin{array}{l}\text { Prospective }{ }^{\mathrm{b}} \\
(\mathrm{N}=1059)\end{array}$ \\
\hline $\begin{array}{l}\text { Many stores within easy walking } \\
\text { distance }\end{array}$ & $2.9(1.1)$ & $1.13(1.04,1.22)^{* *}$ & $1.06(0.94,1.20)$ \\
$\begin{array}{l}\text { Many alternative routes to get to } \\
\text { places }\end{array}$ & $3.3(0.9)$ & $1.12(1.01,1.23)^{*}$ & $1.19(1.03,1.38)^{*}$ \\
$\begin{array}{l}\text { Footpaths on all streets } \\
\text { Park or nature reserve nearby }\end{array}$ & $3.1(1.1)$ & $1.07(0.99,1.15)$ & $0.94(0.82,1.08)$ \\
$\begin{array}{l}\text { Bicycle or walkway tracks nearby } \\
\text { Neighborhood attractive }\end{array}$ & $3.1(1.1)$ & $1.08(1.00,1.17)^{*}$ & $1.10(0.97,1.24)$ \\
$\begin{array}{l}\text { Pleasant natural features in } \\
\text { neighborhood }\end{array}$ & $3.6(0.6)$ & $0.98(0.86,1.13)$ & $1.05(0.84,1.32)$ \\
$\begin{array}{l}\text { Local traffic not making walking } \\
\text { difficult or unpleasant }\end{array}$ & $3.4(0.9)$ & $1.10(0.997,1.22)$ & $1.01(0.86,1.19)$ \\
\begin{tabular}{l} 
Feeling safe to walk during the day \\
\hline
\end{tabular} & $3.8(0.5)$ & $1.18(1.01,1.38)^{*}$ & $0.83(0.62,1.09)$ \\
\hline
\end{tabular}

$* \mathrm{p}<0.05, * * \mathrm{p}<0.01$

${ }^{\mathrm{a}}$ Odds $(95 \% \mathrm{CI})$ of regular walking (5 times/week or more at baseline)

${ }^{\mathrm{b}}$ Odds (95\%CI) of maintaining regular walking (5 times/week or more at baseline and followup) among regular walkers at baseline

Models adjusted for age, gender, education, work status change, child status change, mobility, BMI, and correcting for clustering. All environmental attributes ranged from 1 to 4 (continuous), and were examined separately. 
Table 3 Odds ratios (95\%CI) of regular walking and maintenance of regular walking by environmental attributes: analyses stratified by the change in work status

\begin{tabular}{|c|c|c|c|}
\hline Environmental attributes & $\begin{array}{l}\text { Change in } \\
\text { work status }\end{array}$ & $\begin{array}{l}\text { Cross-sectional }^{\mathrm{a}} \\
(\mathrm{N}=2086)\end{array}$ & $\begin{array}{l}\text { Prospective }^{\mathrm{b}} \\
(\mathrm{N}=823)\end{array}$ \\
\hline \multirow[t]{2}{*}{ Many alternative routes } & Kept working $^{\mathrm{c}}$ & $1.04(0.91,1.20)$ & $1.08(0.86,1.35)$ \\
\hline & Stopped/not working ${ }^{\mathrm{d}}$ & $1.23(1.06,1.42)^{* *}$ & $1.49(1.15,1.93)^{* *}$ \\
\hline \multirow[t]{2}{*}{ Footpaths on all streets } & Kept working ${ }^{c}$ & & $0.87(0.70,1.07)$ \\
\hline & Stopped/not working ${ }^{\mathrm{d}}$ & & $1.13(0.92,1.40)$ \\
\hline \multirow[t]{2}{*}{ Park or nature reserve nearby } & Kept working ${ }^{\mathrm{c}}$ & & $0.78(0.57,1.07)$ \\
\hline & Stopped/not working ${ }^{\mathrm{d}}$ & & $1.17(0.86,1.59)$ \\
\hline \multirow{2}{*}{$\begin{array}{l}\text { Bicycle or walkway tracks } \\
\text { nearby }\end{array}$} & Kept working ${ }^{c}$ & & $0.93(0.76,1.14)$ \\
\hline & Stopped/not working ${ }^{\mathrm{d}}$ & & $1.31(1.07,1.61)^{* *}$ \\
\hline
\end{tabular}

** $\mathrm{p}<0.01$

${ }^{\text {a }}$ Odds (95\%CI) of regular walking (5 times/week or more at baseline)

${ }^{\mathrm{b}}$ Odds (95\%CI) of maintaining regular walking (5 times/week or more at baseline and followup) among regular walkers at baseline

${ }^{c} \mathrm{~N}=1087$ for cross-sectional analysis, 422 for prospective analysis

${ }^{\mathrm{d}} \mathrm{N}=999$ for cross-sectional analysis, 401 for prospective analysis

Models adjusted for age, gender, education, child status change, mobility, BMI, and correcting for clustering. All environmental attributes ranged from 1 to 4 (continuous), and were examined separately. 
Figure

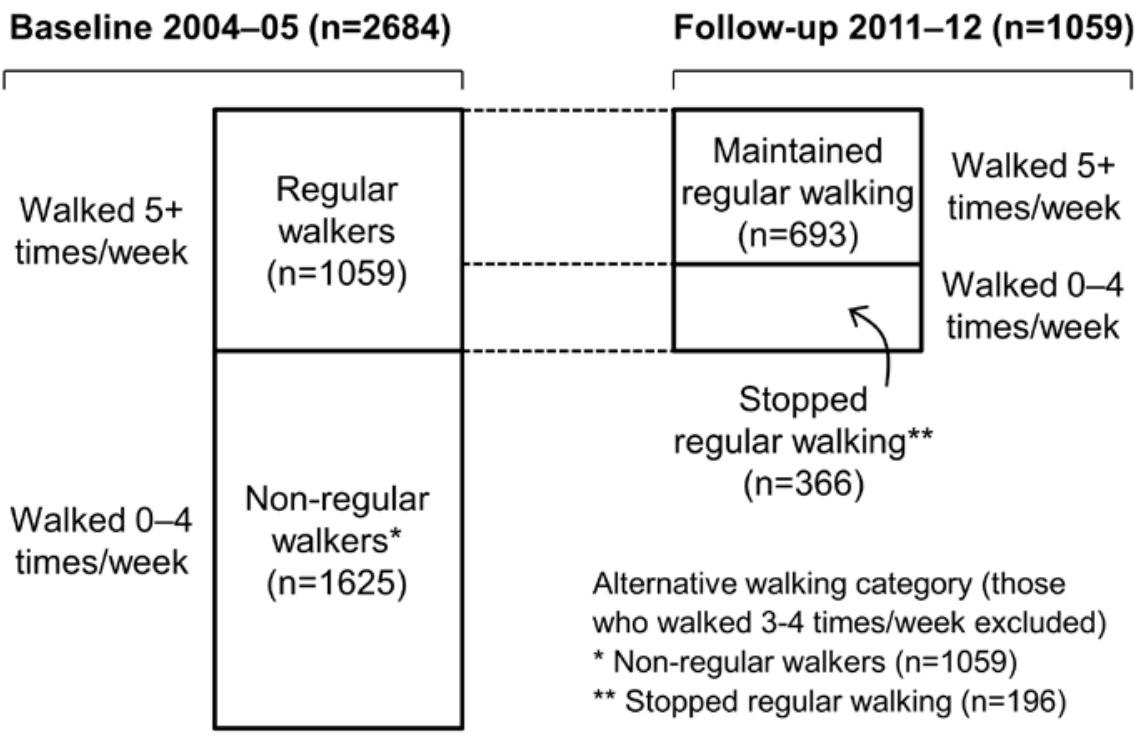

Figure 1. Categorization of participants according to walking frequency 


\section{Supplemental Digital Content (SDC)}

SDC 1. Pearson's correlation coefficients between environmental attributes

\begin{tabular}{|c|c|c|c|c|c|c|c|c|c|}
\hline Environmental attributes & 1 & 2 & 3 & 4 & 5 & 6 & 7 & 8 & 9 \\
\hline 1. Many stores & 1 & & & & & & & & \\
\hline 2. Many alternative routes & $0.46^{* *}$ & 1 & & & & & & & \\
\hline 3. Footpaths on all streets & $0.42^{* *}$ & $0.38 * *$ & 1 & & & & & & \\
\hline 4. Park or nature reserve & $0.29 * *$ & $0.33 * *$ & $0.32^{* *}$ & 1 & & & & & \\
\hline 5. Bicycle or walkway tracks & $0.30 * *$ & $0.35 * *$ & $0.35^{* *}$ & $0.37 * *$ & 1 & & & & \\
\hline 6. Attractive neighborhood & $0.05 *$ & $0.11^{* *}$ & $0.06 *$ & $0.13^{* *}$ & $0.20 * *$ & 1 & & & \\
\hline 7. Pleasant natural features & $0.04 *$ & $0.11^{* *}$ & 0.01 & $0.19 * *$ & $0.26 * *$ & $0.45^{* *}$ & 1 & & \\
\hline $\begin{array}{l}\text { 8. Local traffic not making } \\
\text { walking difficult }\end{array}$ & -0.03 & $0.10 * *$ & 0.03 & $0.10^{* *}$ & $0.08^{* *}$ & $0.18^{* *}$ & $0.15^{* *}$ & 1 & \\
\hline 9. Feeling safe to walk & $0.08^{* *}$ & $0.15^{* *}$ & $0.13^{* *}$ & $0.15^{* *}$ & $0.13^{* *}$ & $0.25^{* *}$ & $0.18^{* *}$ & $0.20 * *$ & 1 \\
\hline
\end{tabular}

${ }^{*} \mathrm{p}<0.05, * * \mathrm{p}<0.001$ 